\title{
Research on improving teaching qualities by using metadata to recognize plants
}

\author{
Shih-Hwa Liu \\ tbrain@tp.edu.tw \\ National Taiwan Normal University \\ Taiwan \\ Jih-Chin Yeh \\ ron.yeh@msa.hinet.net \\ National Taiwan Normal University \\ Taiwan \\ Chao-Chen Chen \\ cc4073@ms73.hinet.net \\ National Taiwan Normal University \\ Taiwan
}

Metadata plays a vital role in the development and implementation of the National Digital Archives Program (NDAP). We're now developing an online database for teaching plant recognition, providing students and other users with an access to recognizing all plants possible. While digitalizing the above-mentioned database, this study focuses on "subject and community oriented" metadata kernel set. By using the exact searching and result revealing interface over the same data as well as cross-database retrieval, we aim at uttering convenience and user-friendliness. In view of the ever-increasing data and the need for future integration, we've tried to analyze the content and features of possible plants, made comparisons over various metadata standards, constructed a user-friendly database system and designed the plant-related metadata in the dedication of research references at home and abroad. The assistant learning mechanism of this interactive digital archive includes two vital aspects. They are, respectively, student-learning circulation and database-learning circulation, which are 
worth developing into further application on teaching. Learners of all levels are able to use the system freely and spontaneously.

For the exchange of the digital archives, this study constructs a Chinese metadata format and integrates XML technique in the hope of helping students retrieve their data precisely, acquire an integrated concept of plants and learn to appreciate and cherish all plants in their campus.

\section{Introduction}

The teaching of plant recognition in elementary and high schools usually goes unnoticed here in Taiwan. Before students get an integrated idea about plans, teachers usually proceed with certain interesting plants or those grown in the campus. Students, however, may come across doubts and difficulties. They might wonder:

1. Why are the classifications of plants so confusing? For instance, why does Alpinia speciosa belong to Zingiberaceae? What family does Oleander belong to? What about Indian Almond?

2. How will I search a certain plant if I don't know the name of it?

3. Is it possible to find related plants in terms of their functions? For instance, how many kinds of ornamental plants are there in Taiwan? What plants bloom in October? What plants possess wind erosion control?

We are trying to build a teaching-assistant system here with resourceful digital content and better search engine in order to improve teaching and learning qualities. The purpose is to arouse students' interest towards plants and learn to search for interrelated information actively and independently.

So far the traditional database concerning plants is not ready to solve the problems above. This most up-to-date archive will provide a much effective solution.

The purpose of this study

1. To find an operative teaching strategy on plant recognition.

2. To find out students' viewpoints and understanding on these teaching methods so as to enhance them more effectively.

3. To improve teaching environment and teaching materials over plant recognition. 


\section{Literature}

\section{The scientific teaching on plants}

Teaching of plant recognition lays strong emphasis on systematic plant classifications, identifications and observations. It also stresses carefulness, truth seeking and plant preservations so that students learn to develop a comprehensive and thorough understanding towards plants.

After explaining the features and characteristics of a certain plant, a teacher can conduct his course by way of experiments. He can remind students to pay keen observations to the plant or have them dissect the internal part of it in order to get a better analysis. He might have them draw an illustration of the plant, if necessary. Students can later come to their own induction through active discussions and finally make a presentation out of it. If given enough room to learn on their own, students themselves can always work out a satisfactory end result, though it may take a longer while to achieve it.

Though all things in the universe are interrelated, it's inevitably essential to categorize them in order to accomplish a concrete description. Categorization is indeed a means of constructing a scientific theory.

Being a theory of experience, syntax divided phenomenon into categories. Vocabulary is the main resource which syntax depends upon (Halliday, 1998). Vocabulary constructs the domain of experience and decides the lines between different sub-domains (Martin, 1998).

Halliday's(1998) investigations into grammatical metaphor take us deeply into the way we construct and expand meanings, starting with representations of concrete experienced events and ending with theoretical worlds populated by abstract entities linked through generalized relations and causalities. Halliday points out that "if something is said to be metaphorical, there must also be something that is not; and the assumption is that to any metaphorical expression corresponds another, or perhaps more than one, that is 'literal'. He finds these processes most strikingly in the development of the modern sciences that have historically created robust virtual worlds of theory from observable material events. He sees the same processes of grammatical metaphor as children learn to participate in our built symbolic environment, particularly as they are introduced to these meaning systems in schools, an institution designed expressly for that purpose. 
A noun group is a syntax resource used to categorize in science area. From the view of syntax structure, a noun group is composed of modifier morpheme and primary morpheme. Take "green plant" as an example. "Green" is modifier morpheme and "plant" is central morpheme. In the structure of noun group, the potential of categories is opened by way of iterative character of modification.

The morphemes of noun modifiers are not only functions as modifications which present the visual information, but also indicate the embedded category structures.

A teacher should show his pedagogical skill by being able to impart profound knowledge in understandable language to his student so that they can comprehend the beauty of a subject they are learning. For the last few decades, scholars and studies have proved that learning environments play a critical role in enhancing students' learning abilities. They are also one of the predictable variations (Fraser, 1998). The technological advances and fast spreading use of the Internet have made digital learning (or e-learning) possible and become a new trend in assisting conventional teaching.

\section{Metadata}

The simplest definition of metadata is that it is data about data. Metadata is used to facilitate the understanding, use and management of data. To make the utmost use of a learning resource, it's best to let a computer system automatically choose a learning unit from the database. The function of metadata is precisely its capability to do so.

With the development and implementation of the National Digital Archives Program (NDAP), Metadata has become one of the indispensable basic studies. E-learning can actually benefit a great deal from this archive. The fundamental function of metadata is in its data searching and retrieval. Generally, we conduct a metadata analysis in terms of its environment of use, function, creation, designation, associated search protocols and its status. (Dempsey \& Heery, 1998).

Thousands of LMS (learning management system) or ERP (content management system) could be found over the Internet because of e-learning. They all tried to find a solution to their problem. Unfortunately, they didn't use the same protocol and were very often incompatible with one another.

However, in 1996 World Wide Web Consortium (W3C) agreed to the use of XML (extension markup language)—a simplified format of SGML(Standard 
Generalized Markup Language)_-in view of its cross-platform features and advantages concerning extensibility, structure, description and validation. XML got the advantages of browsing and transferring of HTML, and get rid of the SGML rules which are not in common use. Facing the different operating system, hardware equipment, application software, diverse input mode, the developer can formulate the tag which corresponds to his requirements and to establish the structured descriptions.

If we were to implement an e-learning environment from the view of technology, the data exchange is not easy. In order to accomplish the information exchange and reused for the system or homogeneous database, it is the best practicable to choose the XML technology which its standard is the unified documented exchange format recommend by W3C.

XSL (Extension Stylesheet Language) and CSS (Cascading Style Sheets) were later introduced by $\mathrm{W} 3 \mathrm{C}$ to help solve the layout problems due to different operating systems. XSL is a typesetting language which designed for XML. CSS also is invented for HTML. XSL and CSS are complemented each other in the typesetting of XML documents.

There are several methods to manipulate XML document, we could classified these methods into four types:

1. File System: for example, DOS directory and file management.

2. Relational Database: there are many kinds of RDBMS.

3. Objective-Oriented management: OODBMS.

4. Specific Database: XDBMS especially designated for XML document.

Though XDBMS is still not standardized, it presented some suitable method to manipulate the XML document. Shien-chiang Yu(2004) evaluated performances by program practicing, the result shows that RDBMS has significant performance to storage and operate XML document than other methods, at least it must be the suitable method before a standardized XDBMS.

The professional of database are data management, maintenance and inquiry. And the professional of XML are data transporting, presenting and the modification of structure. Their comparison is summarized as the follow table (Bai-Hsiun Chen \&. Jen-Shin Hong, 2001) 


\begin{tabular}{|c|c|c|}
\hline & Database technology & XML document \\
\hline $\begin{array}{l}\text { Data insert, } \\
\text { delete, modify }\end{array}$ & $\begin{array}{l}\text { It must be process by way of } \\
\text { specific database system. }\end{array}$ & $\begin{array}{l}\text { It can be edited by any word } \\
\text { processor. }\end{array}$ \\
\hline Data inquiry & $\begin{array}{l}\text { The database technology uses } \\
\text { the SQL syntax or text-based } \\
\text { retrieval techniques method. It's } \\
\text { convenient and powerful. }\end{array}$ & $\begin{array}{l}\text { The inquiry syntax has no } \\
\text { standard and is being developed. } \\
\text { Even though the inquiry tools. } \\
\text { Unless the tools are being } \\
\text { developed to have a good fit of } \\
\text { XML framework. }\end{array}$ \\
\hline $\begin{array}{l}\text { Data transfer to } \\
\text { another platform }\end{array}$ & $\begin{array}{l}\text { Before the data transfer, the } \\
\text { specific database system has } \\
\text { setup up completely. }\end{array}$ & $\begin{array}{l}\text { It's easy to copy and paste any } \\
\text { documents. }\end{array}$ \\
\hline $\begin{array}{l}\text { Modify of } \\
\text { column or tag }\end{array}$ & $\begin{array}{l}\text { In order to keep the consistent } \\
\text { and integrity, it had better not to } \\
\text { modify the attribute of column. } \\
\text { The best status is to accomplish } \\
\text { the framework before input the } \\
\text { data. }\end{array}$ & $\begin{array}{l}\text { It is very simple to add into the } \\
\text { DTD, and then modify the XML } \\
\text { document. }\end{array}$ \\
\hline $\begin{array}{l}\text { Data } \\
\text { management } \\
\text { and } \\
\text { maintenance }\end{array}$ & $\begin{array}{l}\text { The database software has } \\
\text { supply the perfect mechanism }\end{array}$ & $\begin{array}{l}\text { By way of the basic file } \\
\text { management }\end{array}$ \\
\hline $\begin{array}{l}\text { Data } \\
\text { presentation }\end{array}$ & Combined with homepage & $\begin{array}{l}\text { Only need the coordination of } \\
\text { template table }\end{array}$ \\
\hline
\end{tabular}

Table 1: The difference between the technology of database and XML

Learning oriented shall be the main concern in the plan, while the digital technology helps the learning more efficient. Using and forming the retrieval table help students learn the most important tools of categorization ---the category, forming and usage of Retrieval Table. Then, have students collecting plants to form the retrieval table.

Pictures of plants that students capture by digital cameras or cell phones can be compared, analyzed, generalized and intergraded liberally in the system. The initial data that captured by learners can be sent to and confirmed by the experts, then, replied learners via internet. In this mechanism, learners can confirm the data of the plants they have seen correctly. Likewise, the database can be expanded. This interactive learning process could be the best model of digital learning. 


\section{Research content}

The digital archive of plants should be scientific, educational and practical. From educational aspect, plants can be categorized by ornamental, herb, hydrophyte, cashcrop, provenance, toxicity, etc. The concern of plants' attributes vary from each, such as ornamental plants should be stressed on their growing periods and methods; cashcrops should be stressed on the quantity and the value of the harvest; herb plants should be focused on therapy and curative effects, and toxicity plants should be concentrated on toxicity, and detoxify.

The whole idea of the research stresses on how to integrate the necessary attributes of different plants into the metadata, making the XML structure complete and used in all areas possible.

This research is sampled from the plant database of Taipei Botanical Garden(http://tpbg.tfri.gov.tw/Default.aspx?tabid=56). There are Pteridophyta 、 Gymnospermae -Angiospermae, and so on. What we think over is learning, not digital technology which is only a term to promote efficiency.

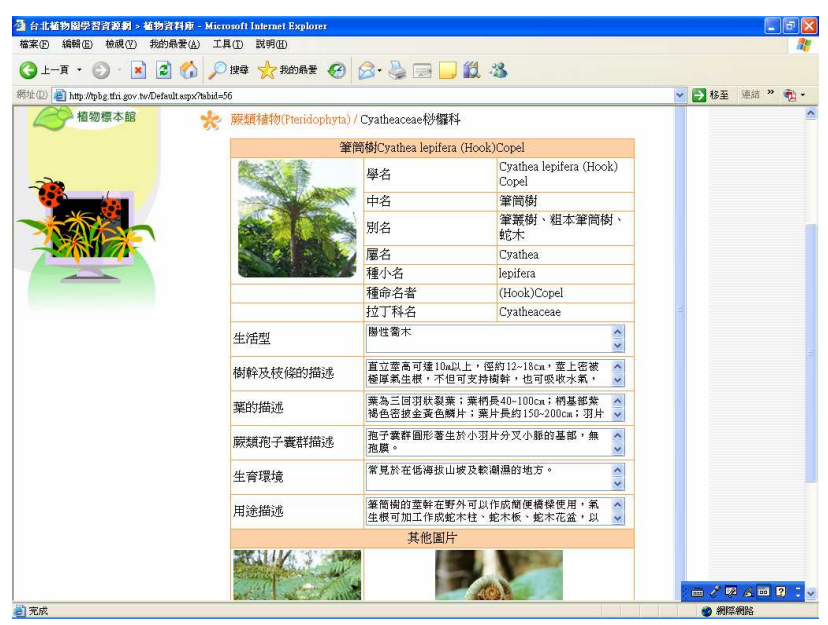

If the student want to query sphaeropteris lepifera (Hook.) Tryon, the specific procedures should be known and proceed to derive the output as follows.

Elements of the Data type definition described as below. 


\begin{tabular}{|c|c|c|c|c|c|c|c|}
\hline \multicolumn{3}{|c|}{ Element name } & \multirow{2}{*}{\multicolumn{2}{|c|}{$\begin{array}{l}\text { Description } \\
\text { Page title }\end{array}$}} & Data type & must & multi \\
\hline \multirow[t]{24}{*}{ plants } & \multicolumn{2}{|c|}{ pagetitle } & & & Character & $*$ & \\
\hline & \multicolumn{2}{|c|}{ phylum } & \multicolumn{2}{|l|}{ Phylum } & Character & & \\
\hline & \multirow[t]{2}{*}{ family } & family_en & \multirow[t]{2}{*}{ Family } & $\begin{array}{l}\text { Family } \\
\text { name in } \\
\text { English }\end{array}$ & Character & & \\
\hline & & family_ch & & $\begin{array}{l}\text { Family } \\
\text { name in } \\
\text { Chinese }\end{array}$ & Character & & \\
\hline & \multicolumn{2}{|c|}{ picture } & \multicolumn{2}{|c|}{ Main picture file } & Character & & \\
\hline & \multicolumn{2}{|c|}{ scien_name } & \multicolumn{2}{|c|}{ Scientific name } & Character & & \\
\hline & \multicolumn{2}{|c|}{ chinese_nam } & \multicolumn{2}{|l|}{ Chinese name } & Character & & \\
\hline & \multicolumn{2}{|c|}{ english_name } & \multicolumn{2}{|l|}{ English name } & Character & & \\
\hline & aliase & alias & aliases & alias & Character & & $*$ \\
\hline & origin & origin & Country of ori & $\begin{array}{l}\text { Country of } \\
\text { origin }\end{array}$ & Character & & $*$ \\
\hline & \multicolumn{2}{|c|}{ genus } & \multicolumn{2}{|l|}{ genus } & Character & & \\
\hline & \multicolumn{2}{|c|}{ species } & \multicolumn{2}{|l|}{ species } & Character & & \\
\hline & \multicolumn{2}{|c|}{ species_namer } & \multicolumn{2}{|l|}{ Species namer } & Character & & \\
\hline & \multicolumn{2}{|c|}{ ordinal } & \multicolumn{2}{|l|}{ ordinal } & Character & & \\
\hline & \multicolumn{2}{|l|}{ tall } & \multicolumn{2}{|l|}{ Life type } & Character & & \\
\hline & \multicolumn{2}{|l|}{ trunk } & \multicolumn{2}{|c|}{ Trunk and branch description } & Character & & \\
\hline & \multicolumn{2}{|l|}{ leaf } & \multicolumn{2}{|c|}{ Leaves description } & Character & & \\
\hline & flowe & & Flower descri] & & Character & & \\
\hline & seed & & Seeds descript & & Character & & \\
\hline & clima & & Climate descri & & Character & & \\
\hline & envirc & & Environment & cription & Character & & \\
\hline & usage & & Usage descrip & & Character & & \\
\hline & others & & Other descript & & Character & & \\
\hline & pics & pic & Other pictures & $\begin{array}{l}\text { Other } \\
\text { picture file }\end{array}$ & Character & & $*$ \\
\hline & Creat & & Creator & & Character & & \\
\hline & Date & & Date of creatic & & Character & & \\
\hline & Form & & Data format(T & T/XML) & Character & & \\
\hline & Langi & & Language & & Character & & \\
\hline & Right & & Copy Rights & & Character & & \\
\hline
\end{tabular}


List below shows content of the DTD file:

$<$ !ELEMENT plants (pagetitle | phylum | family | picture | scien_name | chinese_name | english_name $\mid$ aliases | origins | genus | species | species_namer | ordinal | tall | trunk | leaf | flower | seed | climate | environment | usage | otherspec | pics | Creator | Date | Format | Language | Rights)+>

$<$ !ELEMENT family (family_en | family_ch)+>

$<$ !ELEMENT aliases (alias)*>

$<$ !ELEMENT origins (origin)*>

$<$ !ELEMENT pics (pic)*>

$<$ !ELEMENT pagetitle (\#PCDATA) >

$<$ !ELEMENT phylum (\#PCDATA) >

$<$ !ELEMENT family_en (\#PCDATA) >

$<$ !ELEMENT family_ch (\#PCDATA)>

$<$ !ELEMENT picture (\#PCDATA) $>$

$<$ !ELEMENT scien_name (\#PCDATA)>

$<$ !ELEMENT chinese_name (\#PCDATA)>

$<$ !ELEMENT english_name (\#PCDATA)>

$<$ !ELEMENT alias (\#PCDATA) >

$<$ !ELEMENT origin (\#PCDATA) $>$

$<$ !ELEMENT genus (\#PCDATA) >

$<$ !ELEMENT species (\#PCDATA)>

$<$ !ELEMENT species_namer (\#PCDATA) >

$<$ !ELEMENT ordinal (\#PCDATA) >

$<$ !ELEMENT tall (\#PCDATA)>

$<$ !ELEMENT trunk (\#PCDATA) >

$<$ !ELEMENT leaf (\#PCDATA)>

$<$ !ELEMENT flower (\#PCDATA) >

$<$ !ELEMENT seed (\#PCDATA) >

$<$ !ELEMENT climate (\#PCDATA)>

$<$ !ELEMENT environment (\#PCDATA)>

$<$ !ELEMENT usage (\#PCDATA)>

$<$ !ELEMENT otherspec (\#PCDATA) >

$<$ !ELEMENT pic (\#PCDATA)>

$<$ !ELEMENT Creator (\#PCDATA)>

$<$ !ELEMENT Date (\#PCDATA)>

$<$ !ELEMENT Format (\#PCDATA) > 
$<$ !ELEMENT Language (\#PCDATA)>

$<$ !ELEMENT Rights (\#PCDATA)>

The elements of this DTD can also be compared with Dublin Core, list below shows the relations between both.

\begin{tabular}{|l|l|l|}
\hline$\#$ & Dublin Core & Elements of Plants \\
\hline 1 & Title & pagetitle \\
\hline 2 & Creator & Creator \\
\hline 3 & Subject & chinese_name | english_name \\
\hline 4 & Description & $\begin{array}{l}\text { aliases| origins | genus | species |ordinal | tall } \\
\mid \text { trunk | leaf | flower | seed | climate | } \\
\text { environment | usage | otherspec | pics }\end{array}$ \\
\hline 5 & Publisher & species_namer \\
\hline 6 & Contributor & unmapping \\
\hline 7 & Date & Date \\
\hline 8 & Type & unmapping \\
\hline 9 & Format & Format \\
\hline 10 & Identifier & unmapping \\
\hline 11 & Source & unmapping \\
\hline 12 & Language & Language \\
\hline 13 & Relation & unmapping \\
\hline 14 & Coverage & unmapping \\
\hline 15 & Rights & Rights \\
\hline & & \\
\hline
\end{tabular}

The digital archives database is completed and located at http://140.122.104.15:8080/ug-102.jsp?xsd_name=tree\&start_rec=1\&page_size=10\& sort_order=create-date\&display_mode=brief 


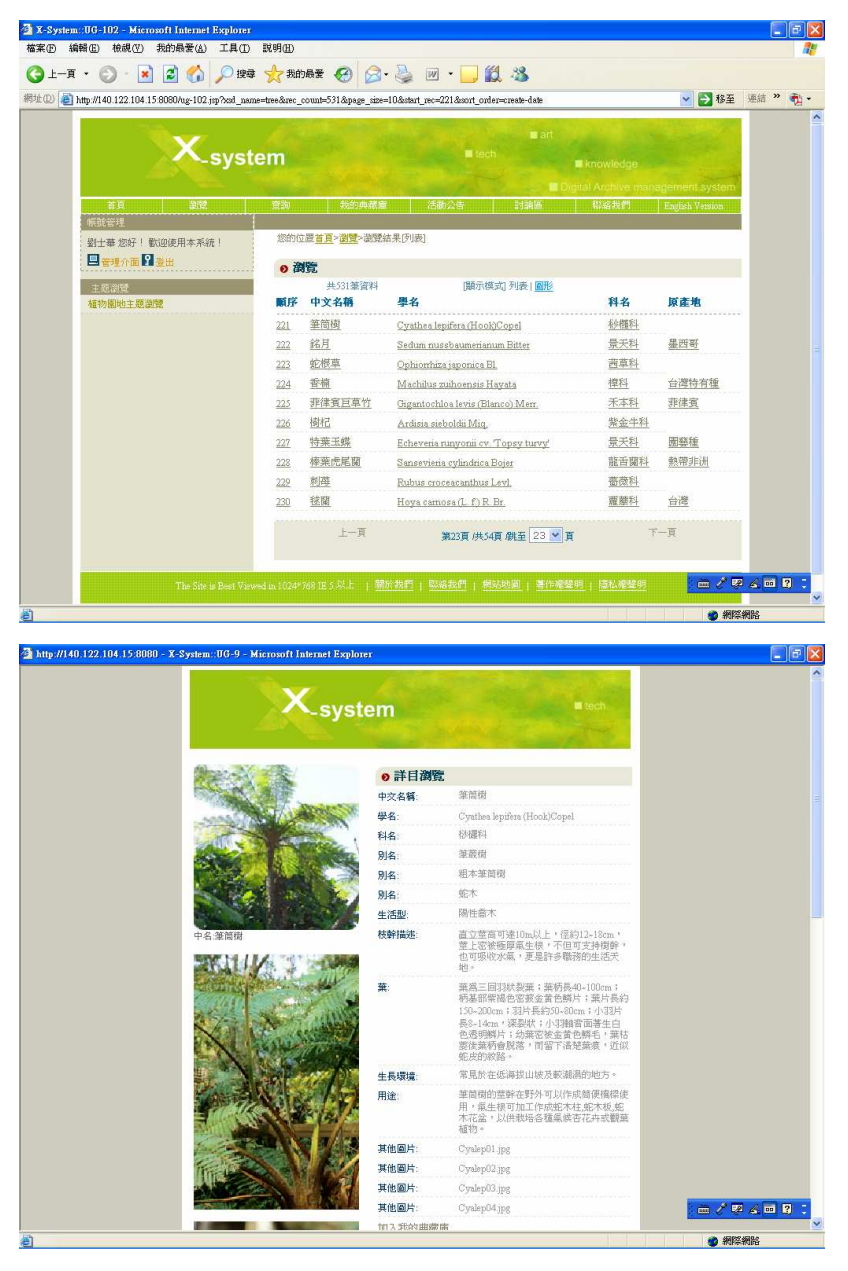

Interactive learning-assistance mechanism is functioned in this plant-recognition database with two types of circulations as follows.

Student-learning circulation:

1. Description of plant photos and observations conducted by students.

2. The above-mentioned description is uploaded to the homepages of the database.

3. It will then search for identical features and characteristics of the plants on the lists.

4. Students can make a further observation, comparison and screening on the plants. Specialists or experts will also provide answers to unidentified plants afterwards.

5. Feedback of thorough information of the plants will be given to students for further study.

Database learning circulation:

1. Any photo and description of a plant uploaded will be recorded in the previous database. 
2. The database will search all the lists for identical features of the plant.

3. Complete identification will be performed in the pervious database.

4. The system will issue a notice confirmed by botanists or specialists to the students who have done their work.

5. The correct photos and description is then added to the database.

6. The previous content is then deleted.

The research result is that the student's conscious about category structure of noun group were not complete. Besides, when the category structure of noun group and the category structure of science community are not correspondent, some students will be hinted by the syntax of noun group and infer a un-exist category structure. Hence, if the guide books want to present the category structure accurately and inspire the students to realize correctly, it had better to investigate any learning stage and the specific modification morpheme before use the noun group.

\section{Conclusion}

This research has been developed in a multi-dimensioned way. The digital archive files are all done artificially, and the functions are focused on structured description and organization. The importance of description is focused on data structure, and covered with the standard of data values, not the data contents. The level of description is mainly focused on archive item instead of its full texts. And these descriptions are all scanned to digital files without any content markup. As a whole, the significances are equally placed between the deep description and the common discovery. The three main functionalities of these metadata standards include the organization of digital information lifecycle, the query and retrieval as well as its usage.

Descriptions on the structures of attributions differ from plant to plant. This study, however, induces attributions of all plants possible and integrates them into one database so that it fits all sorts of plants. We attempt to develop a database standard with its content markup completed in the near future.

Active learning from a student usually creates a more effective and satisfying result. The best learning approach a student can ever apply is get in touch with nature in person. A teacher should guide his students to the categorization of plants rather than teach him too much knowledge of them. He should bring more creativity and novelty in his teaching. Providing students with more room to learn and present by themselves will definitely enhance a teacher's teaching quality. 


\section{Reference}

Bai-Hsiun Chen \&. Jen-Shin Hong(2001). "The virtual presentation of digital museum model, concept and system". In Proceedings of the trend of new century digital library and digital museum, National Chiao Tung University.

Dempsey, L., Heery, R.(1998). "Metadata: a current view of practice and issues". Journal of Documentation, 54(2), 145-172.

Fraser,B.J.(1998). Development of a test of science-releted attitudes. Science Education, 62(4), 509-515.

Hakon Wium Lie, Janne Saarela(1999)," Multipurpose Web publishing using HTML, XML, and CSS”, Commun. ACM 42, 10, Pages 95-101.

Halliday, M. A. K. (1998) Things and relations: Regrammaticising experience as technical knowledge. In Martin, J. R. and R. Veel, Eds. (1998).

Ron Daniel, Carl Loagoze(1997),"From Metadata containers to active digital objects," D-Lib Magazine Novemember.

Serge Abiteboul(1999), "On views and XML", In Proceedings of the eighteenth ACM SIGMOD-SIGACT-SIGART symposium on Principles of database systems, Pages 1-9.

W3C, http://www.w3.org. 